ISSN 2466-2232

Online ISSN 2466-2100

\title{
$\mathrm{Al} / \mathrm{Fe}$ 셀프피어싱 리벳 접합부의 부식특성 및 파괴거동
}

\author{
강 상 훈,*** 윤 진 영***** 김 철 희,+† \\ *한국생산기술연구원 용접접합그룹 \\ **조선대학교 용접접합과학공학과 \\ ***한양대학교 대학원 기계공학과
}

\section{Corrosion Properties and Failure Behavior of Al/Fe Self-Piercing Rivet Joint}

\author{
Sanghoon Kang*,**, Jin Young Yoon*,***, and Cheolhee Kim*, \\ *Joining R\&D group, Korea Institute of Industrial Technology, Incheon, 21999, Korea \\ **Welding and Joining Science Engineering, Chosun University, Kwangju, 61452, Korea \\ ***School of Mechanical Engineering, Hanyang Universty, Seoul, 04763, Korea
}

†Corresponding author : chkim@kitech.re.kr

(Received June 4, 2018 ; Revised June 12, 2018 ; Accepted June 19, 2018)

\begin{abstract}
In the automotive industry, light-weighting of chassis and car body is an inevitable trend to meet the fuel efficiency regulation. Therefore, the use of $\mathrm{Al}$ alloy is increasing and also joining with the conventional steel sheets is getting an important issue. The SPR(self-piercing rivet) joining kinds of mechanical fastening is preferred in $\mathrm{Al} / \mathrm{Fe}$ joint due to different material properties between the $\mathrm{Al}$ and steel as like melting temperature, heat conduction coefficient and thermal expansion coefficient. However galvanic corrosion between rivet and materials is still a big issue to be solved in the SPR joint. In this study, salt spray test (SST) was performed for Al/Fe SPR joint in which $1 \mathrm{~mm}$-thick of Al 6014-T4 and $1.2 \mathrm{~mm}$-thick of GA 590DP steel sheets were joined with PFZn-Ni5L-B coated SPR. The steel sheet was electro-deposition coated prior to the SPR process. In SST up to 80 days, bearing load for tensile-shear test increased with increasing of exposure time, and fracture mode was not varied within the experimental period.
\end{abstract}

Key Words : SPR (Self-piercing Rivet), Al/Fe, Galvanic corrosion, Crevice corrosion, Neutral salt spray test

\section{1. 서 론}

경량화를 통한 연비향상을 위해 차체에 강판 대신 경 금속인 알루미늄, 마그네슘 등의 합금 사용이 증가하고 있다 ${ }^{1-4)}$. 알루미늄은 경량화가 가능하지만 성형성이 강 (steel)에 비해 낮아 차체 적용을 위해서 강과 복합적 으로 사용하려는 연구가 이루어지고 있다. 기존의 용융 용접을 적용하는 경우, 접합 계면에 취성이 강한 금속간 화합물(Intermetallic compound)이 형성되어 물성을 저하시킬 수 있어 이를 대체하고자 클린칭(clinching), 셀프피어싱리벳 (SPR, self-piercing rivet) 등 기계
적 접합과 접착을 채용하고 있다. 그 중 $\mathrm{SPR}$ 접합은 홀가공없이 리벳을 사용하여 상판과 하판을 접합시키는 성형기반의 기계적 접합법으로 금속간의 체결 이외에도 난 용접재인 비금속, $\mathrm{CFRP}$, 플라스틱에도 적용할 수 있다. 또한 기계적 강도 및 피로 강도가 우수하며 접합 속도가 빠르고 ${ }^{2,5,6)}$, 접합부의 열변형이 없으며 친환경 적이기 때문에 많은 연구가 이루어지고 있다5,6).

알루미늄 프레임에 강으로 된 리벳을 사용할 경우 알 루미늄과 강의 전위차에 의해 부식에 취약하다고 보고 된 바 있다. 부식은 금속이 그 주위환경의 여러 가지 물질과의 화학적 또는 전기화학적 반응에 때문에 발생 하는 현상이다. 부식은 전면부식과 국부 부식으로 구분 
할 수 있으며, 국부 부식에는 공식, 선택 부식, 입계 부 식, 갈바닉 부식(Galvanic corrosion), 틈새 부식, 응 력 부식 균열 등이 있다. 이 중 기계적 접합에서는 갈 바닉 부식과 틈새 부식, 응력 부식이 발생할 수 있으며, 부식현상으로 인한 접합부의 성능 및 수명의 저하가 발 생할 수 있다 ${ }^{7,8)}$.

Zheng등은 이종소재 접합을 대상으로 부식시험을 진 행한 바 있으며, 희생 양극 역할을 하는 금속이 산화되 고 이로 인하여 기계적 성능이 저하된다고 발표하였다 ${ }^{7)}$. 반면에 Calabrese등은 기계적 접합한 시편을 염수 분무 시험(Salt spray test)하였을 때, 부식 초기에 접합부 틈새에 염이 침적되고 틈새 부식으로 인해 부식 생성물이 형성되는데 이러한 얇은 염의 침적 층과 산화 물 $\left(\mathrm{Al}_{2} \mathrm{O}_{3}\right)$ 및 수산화물 $\left(\mathrm{Al}(\mathrm{OH})_{3}\right)$ 층이 판재 간의 접 착제 역할을 하면서 접합부의 접합력을 향상해준다고 언급하였다 ${ }^{10,11)}$. 이처럼 선행연구 사이에도 역설이 존 재하여 SPR 접합에 대한 기계적 물성 및 부식특성에 대한 검증이 요구된다. 또한 상기의 연구결과 등은 전 착도장을 하지 않은 상태로 진행되었기 때문에, 실제 부품과의 괴리가 존재한다.

때문에 본 연구에서는 차체 적용을 목적으로 알루미 늄과 강종의 이종소재 $\mathrm{SPR}$ 접합을 수행하고, 접합부의 기계적 특징 및 접합부 부식 거동을 검토하였다. 시험 편의 경우 부식시험 전 전착도장을 선행하였다.

\section{2. 실험 방법}

시험편은 KS B 0854 규격을 기준으로 제작되었다. 제작된 시험편을 Fig. 1에 나타내었다. 상판에 $\mathrm{Al} \mathrm{6014-}$ $\mathrm{T} 4,1.0 \mathrm{~mm}$ 를 배치하였으며, 전착 도장한 $\mathrm{SGAFC}$ $590 \mathrm{DP}, 1.2 \mathrm{~mm}$ 를 하판에 위치시키고 뵐호프사의 Rivset Gen 2를 사용하여 시편을 제작하였다. 리벳은 PFZn-Ni5L을 사용하였으며, 리벳 머리의 지름은 $8.7 \mathrm{~mm}$, 다리의 길이는 $4.6 \mathrm{~mm}$ 이다. 리벳 코팅층의 형상 및 주요 성분을 Fig. 2 와 Table 1과 같다. 모든 시험편은 접합 전 전착도장을 수행한 후 기계적 체결을 하여, 최 대한 실제 부품과 유사한 환경을 모사하고자 하였다. 시 험편은 부식특성을 중점적으로 고찰하기 위하여 모두 동

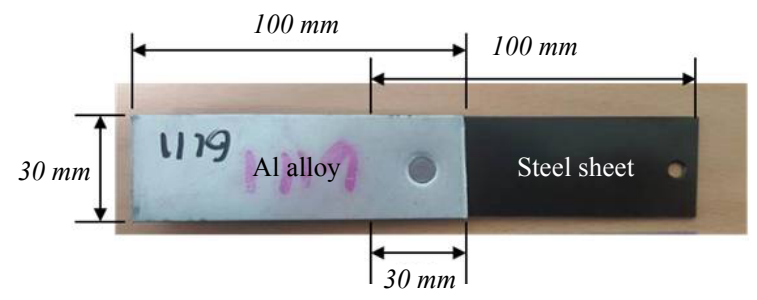

Fig. 1 Dimensions of prepared specimen

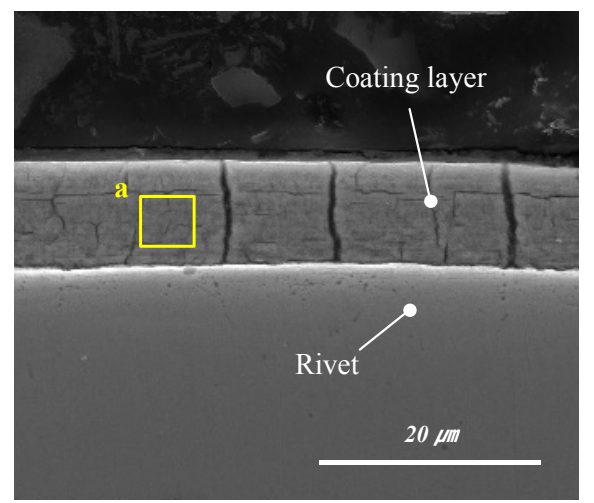

Fig. 2 SEM image of coating layer deposited on SPR

Table 1 Chemical composition of coating layer. Measured point was indicated in Fig. 2-a

\begin{tabular}{|c|c|}
\hline Element & Wt.\% \\
\hline $\mathrm{O}$ & 3.31 \\
\hline $\mathrm{Mo}$ & 2.26 \\
\hline $\mathrm{Fe}$ & 3.23 \\
\hline $\mathrm{Ni}$ & 10.57 \\
\hline $\mathrm{Zn}$ & 80.64 \\
\hline
\end{tabular}

Table 2 Salt spray test conditions

\begin{tabular}{|c|c|}
\hline Operating temperature $\left({ }^{\circ} \mathrm{C}\right)$ & 35 \\
\hline Relative humidity $(\%)$ & 95 \\
\hline $\begin{array}{c}\text { Average collection rate for a horizontal } \\
\text { collecting area of } 80 \mathrm{~cm}^{2}(\mathrm{ml} / \mathrm{h})\end{array}$ & 2.0 \\
\hline Concentration of sodium chloride $(\mathrm{g} / \mathrm{l})$ & 50 \\
\hline $\mathrm{pH}$ & 7.0 \\
\hline
\end{tabular}

일조건에서 제작되었다. 적용한 가압력은 $5,000 \mathrm{kgf} \cdot \mathrm{cm}$ 이며, 툴전진 시 $160 \mathrm{~mm} / \mathrm{s}$, 가압 시 $5 \mathrm{~mm} / \mathrm{s}$ 의 속도로 체결하였다.

부식시험은 KS D 9502:2009 (염수분무시험방법 중성, 아세트산 및 캐스 분무시험)과 ISO 9227:2006 (Corrosion test in artificial atmosphere - Salt spray test)를 참고하여 수행하였으며, 세부 테스트 조건은 Table 2 와 같다. 부식특성 분석은 초기 상태로부터 10 , $20,40,80$ 일 간격으로 시험편을 꺼내어 실시하였다. 광 학현미경을 이용하여 단면 분석을 수행하였으며, SEM$\mathrm{EDS}$ 분석을 통하여 염수층의 침투 깊이 및 리벳 코팅 층 상태를 확인하였다. 이를 통해 부식시간에 증가에 따른 부식의 침투경로에 대해 고찰하고자 하였다. 제작 된 시험편의 기계적 특성을 평가하기 위하여, 염수 분 무 경과일에 따른 인장강도의 변화를 분석하였다. 인장 시험 결과는 조건별로 3 회 반복실시하여 평균값으로 나 타내었다. 

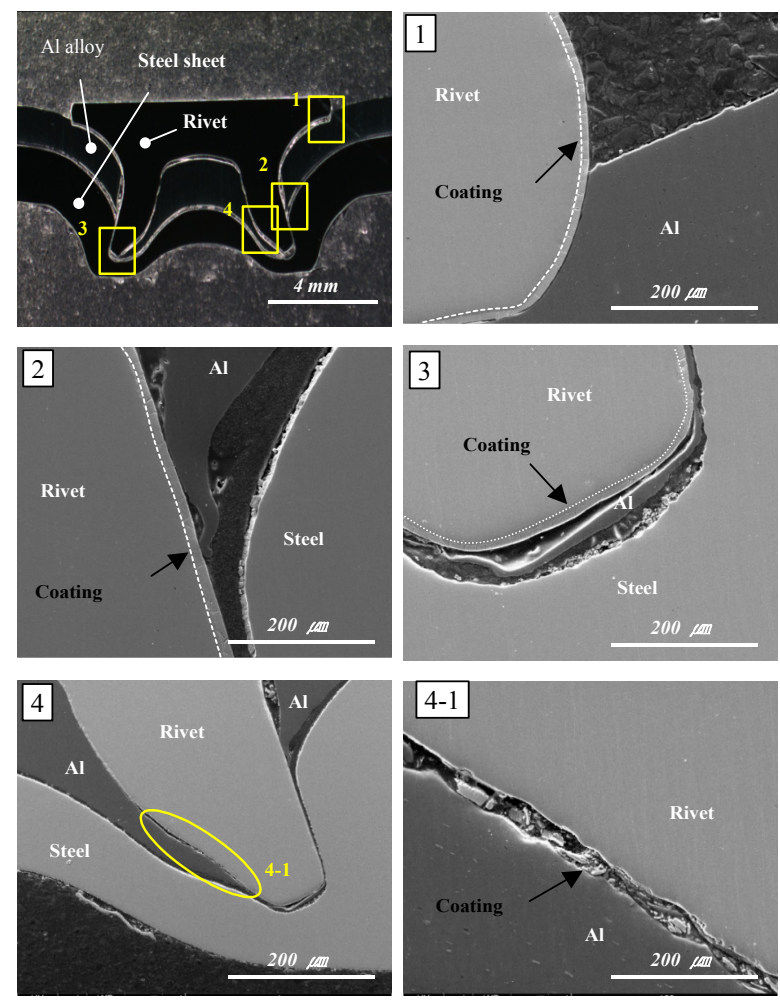

Fig. 3 SEM images of SPR coating layer after riveting

\section{3. 실험 결과 및 고찰}

\subsection{SPR 공정이 리벳 코팅층에 미치는 영향}

알루미늄 프레임에 강으로 된 리벳을 사용할 경우 알 루미늄과 강의 전위차에 의해 전위차 부식이 발생하게 되는데, 리벳에 코팅하면 전위차 부식을 억제할 수 있 다. 그러나 $\mathrm{SPR}$ 공정은 소성변형 기반의 기계적 체결법 이기 때문에 코팅층이 SPR 공정 중 손상 혹은 박리될 수 있다. Fig. 3에 SPR 리벳공정 중 많은 변형이 발 생할 것으로 예측되는 영역을 임의로 선별하여 코팅층 의 형상을 나타내었다. SEM 이미지를 통하여 가압이 가해지는 리벳 헤드 (Fig. 3(a))와 압축응력이 가해지 는 리벳 다리 (Fig. 3(b)-(c))의 외벽에는 균일한 두 께의 코팅층이 잔존하고 있음이 확인되었다. 반면 다이 에 의해 벌어지는 인장 응력이 작용하는 리벳 다리 (Fig. 3(d)) 안쪽에서는 코팅층의 손상이 존재하였다.

\subsection{SPR 접합부의 기계적 특성}

$\mathrm{SPR}$ 기계적 접합부의 염수 분무 경과일에 따른 인장 전단시험 결과는 Fig. 4와 같다. 접합 직후의 강도는

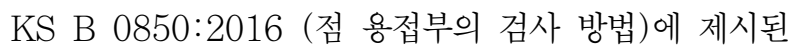
$270 \mathrm{MPa}$ 급 알루미늄 합금의 점용접부 요구 강도와 같

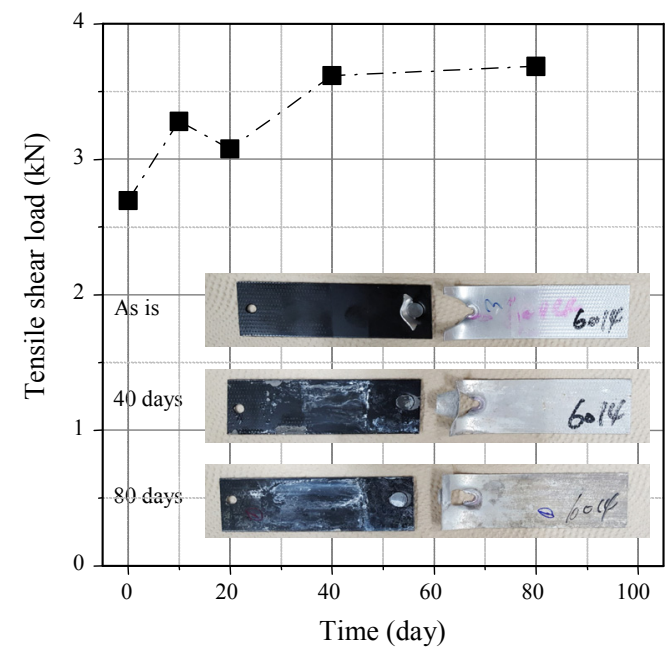

Fig. 4 Measured tensile-shear load results according to exposure time of corrosion environment

다. 접합부의 강도는 염수 분무 시간이 경과함에 따라 인장 강도가 상승하였다. 이러한 결과는 L.Calabrese의 연구와 같은 결과를 보인다 ${ }^{10,11)}$.

L.Calabrese은 부식 초기에는 판재 사이에서 형성된 부식생성물의 부피팽창으로 인해 언버튼(unbuttoning) 파단이 주요하게 발생한다고 하였으며 ${ }^{3)}$, 접합부의 두께 가 얇은 경우는 베어링(bearing) 파단이 발생하고 부식이 더욱 진행되면서 균열의 전파로 인해 인장(net-tension) 파단 또는 전단(shear out)파단도 함께 발생한다고 하 였다 $3,8,10,11$. 그러나 해당 연구에서 접합부의 파단은 염수분위기 노출 시간과 무관하게 베어링 파단 모드가 발생하였다. 이는 볼트 또는 리벳이 삽입된 구멍 주변 에 응력이 집중되어 발생하는 파단으로써, 실험이 진행 된 80 일 기간 내에서의 부식 정도가 기계적 특성에 큰 영향을 미치지 못하였음을 의미한다. 염수 분무 노출 시간에 따른 인장 파단시험편의 계면 사진을 Fig. 5에 나타내었다.

\subsection{SPR 접합부의 부식특성}

$\mathrm{SPR}$ 접합에서 염수가 침투할 수 있는 경로를 Fig. 6에 나타내었다. 알루미늄판과 강판 사이 또한 전위차 에 의한 갈바닉 부식과 틈새 부식이 발생할 수 있으나, 실험에서 사용된 강재는 전착 도장을 하여 해당 영역에 서의 전위차 부식을 배재할 수 있기 때문에 조사되지 않았다. 전위차 부식과 틈새 부식이 발생할 수 있는 I영역과 II-영역을 중심으로 분석을 수행하였다. I-영역 은 리벳 헤드 부분으로 리벳과 접촉한 부재와의 전위차 로 갈바닉 부식이 발생할 수 있으며, II-영역은 리벳과 강판, 알루미늄판이 교차하는 영역으로 틈새부식 주로 


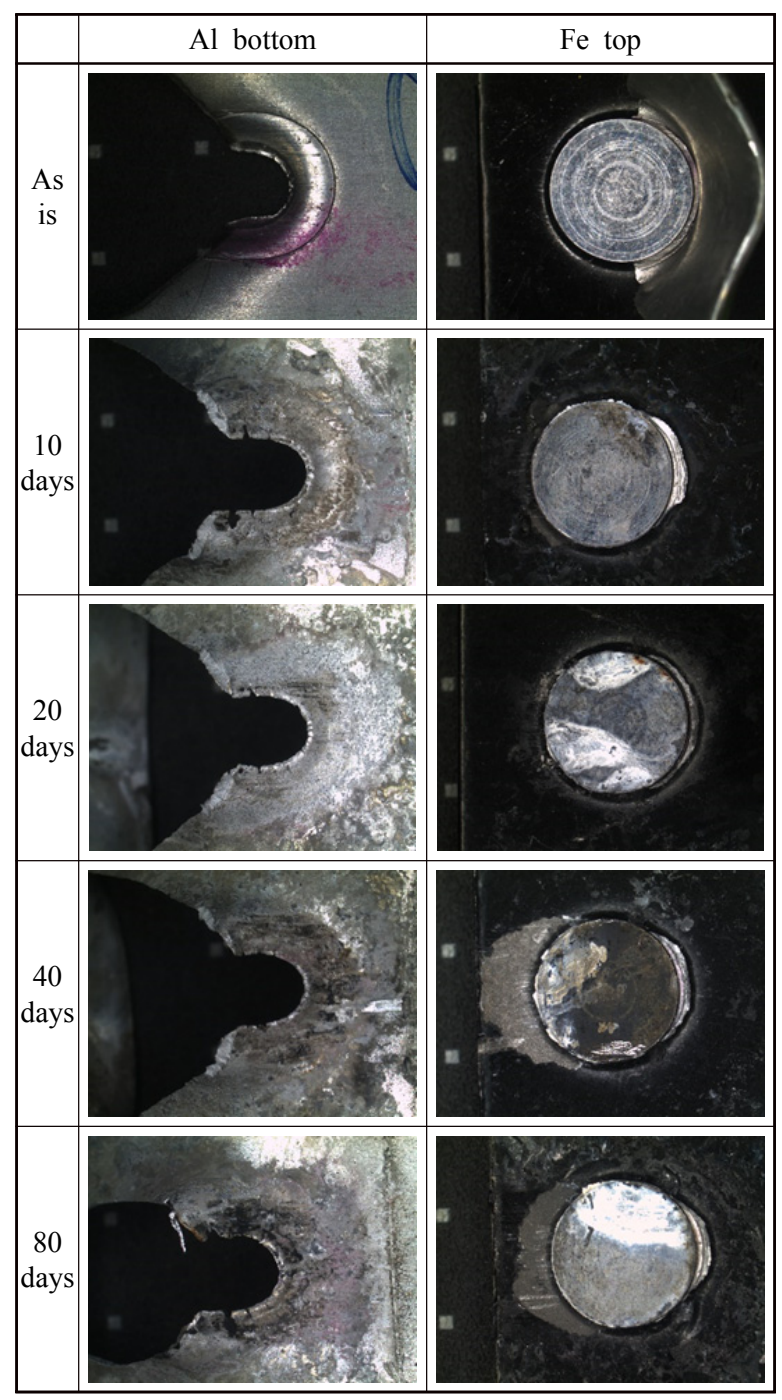

Fig. 5 Fracture images at interfacial surface between aluminum and steel sheet after tensile-shear test

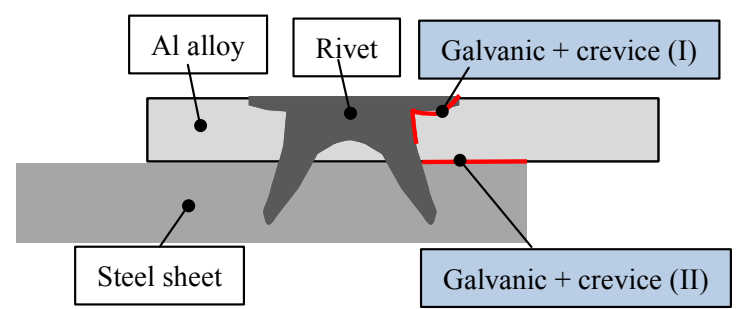

Fig. 6 Schematic diagram of corrosion propagation route

확인되는 곳이다.

I-영역의 부식 진행도는 Fig. 5의 파단부 계면 사진 을 통해 확인할 수 있었다. 20 일이 경과한 시험편까지 $\mathrm{SPR}$ 홀 주변에 손상이 없음이 확인되었다. 부식시간이 40 일 이상으로 증가하면 부식환경의 영향을 받아 알루 미늄 표면이 검게 산화되는 것을 관찰할 수 있다. 그러 나 앞서 언급한 것과 마찬가지로 SPR 홀주변의 부식
정도는 풀아웃 파단이 발생하지 않을 정도로 미미하였다. 염수 침투 경로인 I, II-영역 및 리벳 다리 첨단에서 의 O 성분을 SEM-EDS 분석하고 Fig. 7에 나타내었 다. 염수 환경 노출 시간의 증가에 따라 I, II-영역에서 는 $\mathrm{O}$ 성분이 증가하는 경향이 뚜렷이 나타났다. 그러나 리벳의 끝단에서는 노출 시간과 무관하게 $\mathrm{O}$ 성분이 균 일하게 분포되어 있음이 확인되었다. 부식은 리벳 내부 로 침투하지 못했으며, 이것은 리벳의 코팅층 손상이 없 기 때문으로 판단된다. 성분분석 결과를 통해 염수가 I영역과 II-영역을 통해서 침투되지만, 실험범위인 80일 의 시간 이내에서는 리벳 끝단까지 전파되지 못함을 알 수 있었다. 부식은 리벳의 코팅층-알루미늄, 강재-알루 미늄과의 접촉부에서 시작되며 알루미늄 내부로 확장된다.

\section{4. 결 론}

후드 등의 무빙계를 중심으로 알루미늄의 차체 적용 이 증가하는 추세에 있다. 때문에 알루미늄/강의 이종 접합 공정기술에 대한 수요가 증가하고 있으며, 그 중 기계적 체결법은 소재의 특성에 민감하지 않아 이종재 료 접합에 유용하다고 알려져 있다. 그러나 $\mathrm{SPR}$ 을 이 종접합에 적용하는 경우, 리벳과 알루미늄, 리벳과 강 재, 강재와 알루미늄 사이의 전위차 부식 및 틈새 부식 이 발생할 수 있기 때문에 기계적 물성 및 부식특성에 대한 검증이 요구된다.

본 연구에서는 알루미늄/강 이종소재 SPR 접합에서 부식 노출시간에 따른 기계적 물성 및 부식특성을 확인 하는 것을 목표로 하였다.

1) 부식은 리벳의 코팅층-알루미늄, 강재-알루미늄과 의 접촉부에서 시작되며 알루미늄 내부로 확장된다. 도 금된 리벳을 이용하여 SPR 공정을 하는 경우, 인장 응 력이 작용하는 리벳 다리 안쪽의 코팅층이 손상된다. 그러나 성분분석결과, 리벳 다리 끝단에서는 노출 시간 과 무관하게 $\mathrm{O}$ 성분이 균일하게 분포되어 있음이 확인 되었다. 이것은 부식이 리벳 내부로 침투하지 못하였음 을 의미한다.

2) 실험 범위 이내에서는 염수분무 노출 시간이 경과 함에 따라 인장강도가 상승하는 경향이 나타났다. 이것 은 판재 사이의 접합부 틈새에 얇은 염의 침적 층과 산 화물 및 수산화물이 접착제 역할을 하였기 때문이다. L.Caabrese등은 부식 초기와 후기에 파단모드가 변경 된다고 하였으나, 이러한 현상은 확인되지 않았다. 이 것은 해당 실험범위인 80 일 내에서 알루미늄의 부식으 로 인한 두께손실이 나타나지 않았기 때문으로 판단된 


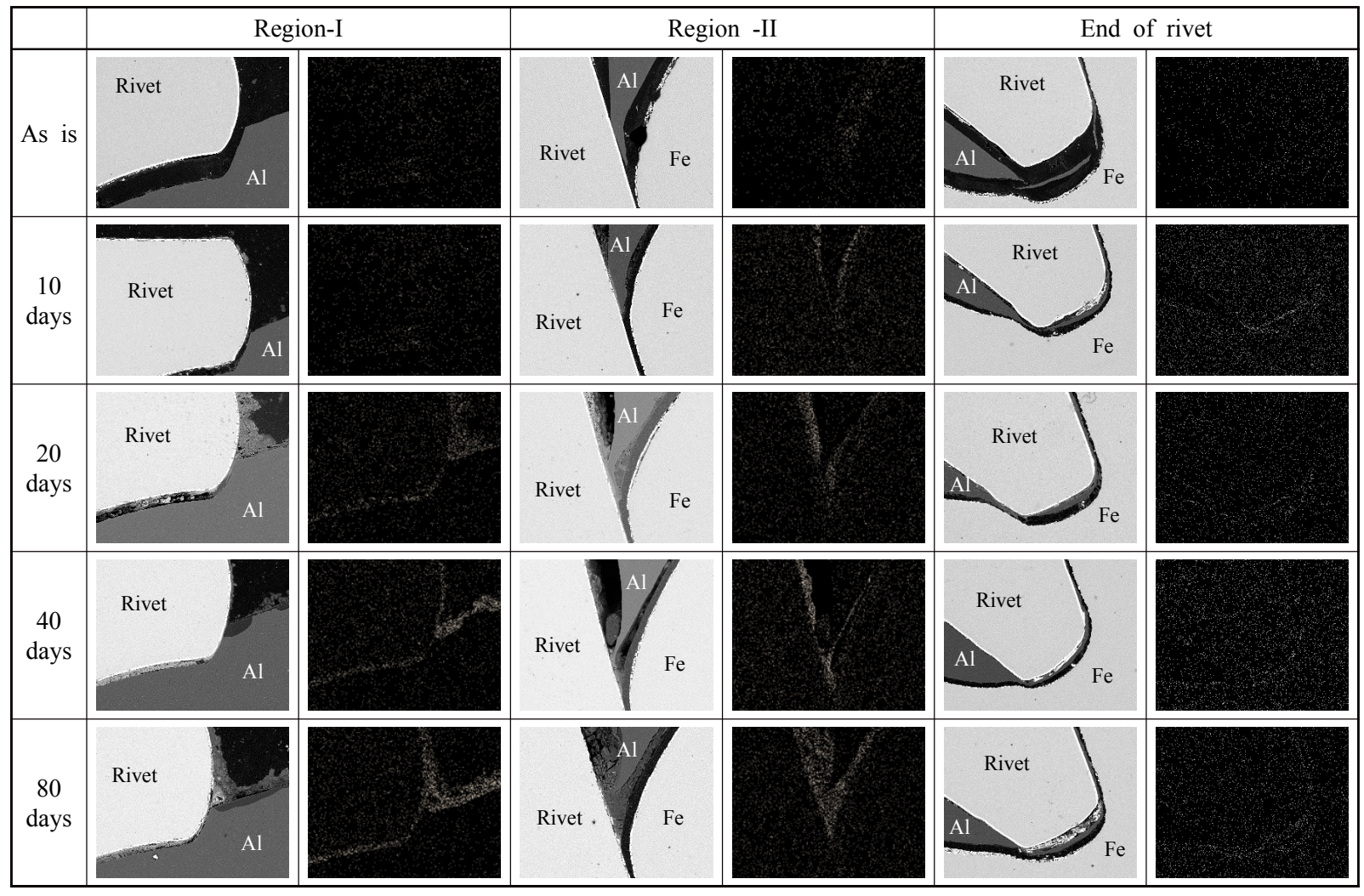

Fig. 7 SEM-EDS mapping analysis of arbitrary region according to the corrosion exposure time

다. 즉, 강재에 전착도장을 처리하는 방법만으로도 부 식을 상당 부분 억제할 수 있다.

ORCID: Sanghoon Kang: http://orcid.org/0000-0002-2566-4570 ORCID: Jin Young Yoon: http://orcid.org/0000-0001-6362-3086 ORCID: Cheolhee Kim: http://orcid.org/0000-0003-4127-3171

\section{References}

1. K. Martinsen, S. J. Hu and B. E. Carlson, Joining of dissimilar materials, CIRP Annals, 64(2) (2015), 679-699 https://doi.org/10.1016/j.cirp.2015.05.006

2. L. Han and A. Chrysanthou, Evaluation of quality and behaviour of self-piercing riveted aluminium to high strength low alloy sheets with different surface coatings, Materials \& Design, 29(2) (2008), 458-468 https://doi.org/10.1016/j.matdes.2006.12.020

3. L. Calabrese, E. Proverbio, G. Di Bella, G. Galtieri and C. Borsellino, Failure behaviour of SPR joints after salt spray test, Engineering Structures, 82 (2015), 33-43 https://doi.org/10.1016/j.engstruct.2014.10.020

4. T.-H. Kim, J. Suh, H.-S. Kang, Y.-S. Lee and C.-D. Park, Fatigue Assessment Using SPR and Adhesive on Dissimilar Materials, Journal of the Korean Society for Precision Engineering, 28(10) (2011), 1204-1209

5. J.-H. Bae, J.-W. Kim, I. Choi, D.-G. Kim and Y.-D. Park, A study on Tensile Shear Characteristics of Dissimilar
Joining Between Pre-coated Automotive Metal Sheets and Galvanized Steels with the Self-Piercing Rivet and Hybrid Joining, Journal of Welding and Joining, 34(1) (2016), 59-67

https://doi.org/10.5781/JWJ.2016.34.1.59

6. D. Kim, Y. Qiu and H.-Y. Cho, Design of self-piercing rivet to joint in advanced high strength steel and aluminium alloy sheets, Journal of Welding and Joining, 33(3) (2015), 75-80 https://doi.org/10.5781/JWJ.2015.33.3.75

7. L. Calabrese, L. Bonaccorsi, E. Proverbio, G. Di Bella and C. Borsellino, Durability on alternate immersion test of self-piercing riveting aluminium joint, Materials \& Design, 46 (2013), 849-856

https://doi.org/10.1016/j.matdes.2012.11.016

8. L. Calabrese, E. Proverbio, E. Pollicino, G. Galtieri and C. Borsellino, Effect of galvanic corrosion on durability of aluminium/steel self-piercing rivet joints, Corrosion Engineering, Science and Technology, 50(1) (2014), 10-17 https://doi.org/10.1179/1743278214Y.0000000168

9. W. Y. Zheng, C. Derushie, J. Lo and E. Essadiqi, Corrosion protection of joining areas in magnesium die-cast and sheet products, in Materials Science Forum, (546, Trans Tech Publ, City, 2007), 523-528

https://doi.org/10.4028/www.scientific.net/MSF.546-549.523

10. L. Calabrese, E. Proverbio, G. Di Bella, G. Galtieri and C. Borsellino, Assessment of ageing effect on the me- 
chanical behaviour of steel/aluminium self-piercing riveted joint, International Journal of Mechanical and Materials Engineering, 10(1) (2015)

https://doi.org/10.1186/s40712-015-0034-y
11. L. Calabrese, E. Proverbio, G. Galtieri and C. Borsellino, Effects of ageing on mechanical durability of round clinched steel/aluminium joints, International Journal of Mechanical and Materials Engineering, 9(1) (2014), 23 https://doi.org/10.1186/s40712-014-0023-6 